\title{
Producción de metano a partir de desechos orgánicos generados en el Tecnológico de Costa Rica
}

\author{
Rossy Guillén Watson' \\ Olga Rivas Solano ${ }^{2}$
}

Fecha de recepción: 17 de mayo del 2011 Fecha de aceptación: 27 de octubre del 2011

Guillén, R; Rivas, O. Producción de metano a partir de desechos orgánicos generados en el Tecnológico de Costa Rica. Tecnología en Marcha. Vol. 25, № 2. Abril-Junio 20 I2. Pág 73-79.

Ingeniera en Biotecnología. Actualmente continúa sus estudios de licenciatura en el Tecnológico de Costa Rica. Teléfono: 8895-9625. Correo electrónico: gosyl6@gmail.com

2 Profesora investigadora. Centro de Investigación en Biotecnología. Escuela de Biología. Tecnológico de Costa Rica. Teléfono 2550-2479. Correo electrónico: orivas@itcr.ac.cr 


\section{Resumen}

En la planta de tratamiento de aguas residuales del Tecnológico de Costa Rica (TEC) se instalaron cuatro biodigestores a escala. Los biodigestores se numeraron como I, 2, 4 y 5. Todos los biodigestores se alimentaron manualmente dos veces por semana durante dos meses. A los biodigestores I y 5 se les agregó una mezcla de agua residual y lirios acuáticos (Eichhornia crassipes) previamente triturados y desecados. Los biodigestores 2 y 4 se alimentaron con agua residual solamente. La producción de metano se midió utilizando un analizador de gases portátil y los parámetros asociados a la degradación de materia orgánica se caracterizaron utilizando los protocolos descritos por Clesceri y colaboradores (2005).

Al final del periodo de evaluación, los biodigestores I y 5 presentaron una concentración de metano cercana al 50\%, mientras que en los biodigestores 2 y 4 fue de aproximadamente 30\%. Estos resultados indican que la adición de lirios como fuente de carbono mejoró la calidad del biogás. Sin embargo, para lograr una mejor degradación de la materia orgánica, se recomienda aumentar el tiempo de retención. Además se recomienda estudiar la productividad metanogénica de otras combinaciones de desechos que también se producen en la institución, como por ejemplo los residuos de la soda comedor.

\section{Palabras clave}

Metano, biodigestor a escala, aguas residuales, lirios acuáticos, energías renovables.

\section{Abstract}

Four small-scale biodigestors were installed at the wastewater treatment plant of the Technological Institute of Costa Rica (TEC). The four biodigestors were named as I,2,4 and 5.All of them were manually fed twice a week during two months. Biodigestors 1 and 5 were fed with a mixture of wastewater and triturated aquatic lilies (Eichhornia crassipes). Biodigestors 2 and 4 were fed with wastewater only. Methane production was measured using a portable gas detector. The parameters related with biological degradation of organic matter were determined following the protocols described by Clesceri et al. (2005).

Biodigestors I and 5 showed methane concentration of $50 \%$, while biodigestors 2 and 4 only reached a methane concentration of $30 \%$. Those results suggested that the addition of plant debris as carbon source improved biogas quality. However, in order to further improve the biological degradation of organic matter, we recommend increasing the retention time. We also recommend studying the methanogenic productivity of other combinations of residues also generated at the university, like food wastes from the institutional restaurant.

\section{Key words}

Methane, small-scale biodigestor, wastewater, aquatic lilies, renewable energies. 


\section{Introducción}

Los desechos orgánicos de origen vegetal y animal se pueden transformar, por acción microbiana, en una mezcla de gases denominada biogás. El biogás se compone de metano y otros compuestos como dióxido de carbono, amoníaco, nitrógeno y sulfuro de hidrógeno (Bidlingmaier, 2006; Soria et al., 200 I).

En este proceso, conocido como digestión anaerobia o biodigestión, intervienen cuatro grupos de microorganismos diferentes. El primero consiste en una mezcla de bacterias llamadas hidrolíticas o formadoras de ácidos, las cuales hidrolizan las moléculas complejas de la materia orgánica para formar ácidos grasos de cadena corta y alcohol. El segundo grupo es el de las bacterias acetogénicas que producen acetato e hidrógeno.

Al tercer grupo se le denomina bacterias homoacetogénicas, ya que convierten un amplio espectro de compuestos orgánicos en ácido acético. Las bacterias metanogénicas constituyen el último eslabón de la cadena de microorganismos encargados de digerir la materia orgánica y devolver al medio los elementos básicos para reiniciar el ciclo, ya que estas bacterias tienen la capacidad de convertir el ácido acético en metano y dióxido de carbono (Weiss et al., 2009, Sosa et al., 1999; Hilbert, 1998, Antoni et al., 2007).

La operación estable de los biodigestores requiere que todos los grupos bacterianos anteriormente descritos estén en equilibrio. Cualquier cambio en las condiciones ambientales puede afectarlo, resultando en una producción desproporcionada de compuestos intermedios que inhiben la formación de metano (Coto et al., 2009).

Durante el 2009 y el 20 I 0, en el Tecnológico de Costa Rica (TEC) se realizó un proyecto de investigación denominado Sistema de vigilancia, control y protección para la purificación, compresión y envasado de metano empleando comunicación inalámbrica bajo protocolos de seguridad OSHA, NFPA.

Este proyecto fue financiado por la Vicerrectoría de Investigación y Extensión (VIE) y contó con la participación de investigadores de las Escuelas de Ingeniería Electrónica, de Biología, de Química, y de Seguridad e Higiene Ocupacional.

Como parte del componente biológico de dicho proyecto, en la planta de tratamiento de aguas residuales del TEC, se instalaron cuatro biodigestores a escala, los cuales se alimentaron con diferentes combinaciones de aguas residuales y desechos vegetales obtenidos de la misma planta de tratamiento.

El objetivo consistió en evaluar la calidad del biogás producido en los cuatro biodigestores a escala, en función de la concentración de metano y la eficiencia de la degradación de materia orgánica, para determinar la factibilidad de obtener compuestos con alto valor energético a partir de los desechos orgánicos generados en la misma institución.

\section{Materiales y métodos}

Instalación de los biodigestores a escala en la planta de tratamiento de aguas residuales del TEC Los cuatro biodigestores a escala se instalaron en la planta de tratamiento de aguas residuales del TEC, en la provincia de Cartago, en la Región Central de Costa Rica a una altura de 1435 msnm, con una temperatura promedio de $19.2^{\circ} \mathrm{C}$ y una precipitación anual de 1500 - 2000 mm (Instituto Meteorológico Nacional, 2008).

La planta de tratamiento consta de dos lagunas conectadas en serie. La primera es anaerobia y está cubierta con lirio acuático (E. crassipes), mientras que la segunda es facultativa (Deloya, 2009). Además, existe otra laguna que trata las aguas domesticas provenientes del residencial Iztarú, que se encuentra ubicado en los alrededores del TEC.

Para la construcción de cada biodigestor a escala, se utilizaron dos bolsas plásticas de $90 \times 145 \mathrm{~cm}$, un adaptador macho de PVC de $1 / 2$ ", un adaptador hembra de PVC de $1 / 2$ ", un codo $90^{\circ}$ de PVC de $1 / 2$ ", una llave de paso de PVC de 1/2", $50 \mathrm{~cm}$ de tubo de PVC de 1/2", pegamento para PVC, $60 \mathrm{~cm}$ de tubo de PVC de $2 "$ y tres codos de $90^{\circ}$ de PVC de 2". Se construyeron siguiendo el modelo de tipo Taiwán. Las dimensiones fueron de $70 \mathrm{~cm}$ de largo, $37 \mathrm{~cm}$ de ancho y $40 \mathrm{~cm}$ de alto. Cada uno tuvo una capacidad de 80 I de fase líquida y de 20 I de fase gaseosa.

\section{Alimentación de los biodigestores a escala}

Todos los biodigestores a escala se alimentaron de forma manual dos veces por semana durante dos meses, ya sea con una mezcla de agua residual y 
lirios acuáticos (E. crassipes) previamente triturados y desecados, o bien, con agua residual solamente.

Al biodigestor I se le agregó una mezcla de 7.8 I de agua residual del TEC y $200 \mathrm{~g}$ de los lirios triturados y desecados (cuadro I). Al biodigestor 2 se le adicionaron 8 I de agua residual del Residencial Iztarú. El biodigestor 4 se alimentó con ocho litros de agua residual del TEC. Al biodigestor 5 se le agregó una mezcla de 7.8 I de agua residual del Residencial Iztarú y 200 g de los lirios triturados y desecados.

Cuadro I. Cantidad y tipo de desecho orgánico empleado para la alimentación de los biodigestores a escala delTEC.

\begin{tabular}{|c|c|c|c|}
\hline \multirow{2}{*}{ Biodigestor } & \multicolumn{3}{|c|}{ Cantidad y tipo de desecho } \\
\cline { 2 - 4 } & AR*-TEC & $\begin{array}{c}\text { AR*- } \\
\text { Iztarú }\end{array}$ & $\begin{array}{c}\text { Lirios } \\
\text { triturados }\end{array}$ \\
\hline 1 & 7.8 I & - & $200 \mathrm{~g}$ \\
\hline 2 & - & 8 I & - \\
\hline 4 & 8 I & - & - \\
\hline 5 & - & 7.8 I & $200 \mathrm{~g}$ \\
\hline
\end{tabular}

*AR: Agua residual.

Las aguas residuales, tanto del TEC como del Residencial Iztarú, se tomaron a la entrada de las respectivas lagunas que les dan tratamiento.

Los lirios se colectaron en la planta de tratamiento del TEC y se pasaron por un triturador de residuos orgánicos industrial (Trapp, TR200). Luego se pusieron a escurrir y se dejaron secar a temperatura ambiente por 2 a 3 días antes de utilizarlos.

En los cuatro biodigestores a escala, el tiempo de retención establecido fue de 10 días.

Medición del metano producido en los biodigestores a escala

Las mediciones de metano se realizaron durante el periodo comprendido entre el día 39 y el día 55, después de iniciada la alimentación de los biodigestores. Para ello se utilizó un equipo portátil para detección de gases (Enmet, RECON/4).

Determinación de los parámetros asociados a la degradación de materia orgánica

Cada vez que se realizó la alimentación manual de los biodigestores a escala, se midió la temperatura con un termómetro de mercurio y el $\mathrm{pH}$ con un pHmetro portátil (DIGISYSTEM, pH50 | A).
Dos meses después de haber iniciado la alimentación de los biodigestores a escala, se tomaron muestras de los influentes y efluentes de cada uno y se determinó la Demanda Biológica de Oxígeno (DBO), la Demanda Química de Oxígeno (DQO),y el contenido de Sólidos Totales (ST).

Estos análisis se efectuaron en el Laboratorio de Aguas Residuales del Centro de Investigación y de Servicios Químicos y Microbiológicos (Ceqiatec), de acuerdo con los procedimientos descritos por Clesceri y colaboradores (2005).

\section{Resultados y discusión}

Producción de metano en los biodigestores a escala

Durante todo el periodo de medición, el biodigestor I presentó el mayor porcentaje de metano en comparación con los demás (figura I).

Sin embargo, en el biodigestor I hubo dos disminuciones drásticas los días 4 I y 48, seguidas por un pico máximo de productividad metanogénica de aproximadamente 70\% el día 49. Posteriormente, a partir del día 50, se observó una tendencia decreciente hasta alcanzar un porcentaje de metano cercano al 50\%.

Los biodigestores 2 y 4 , por su parte, mostraron una producción de metano con tendencia creciente durante la mayor parte del periodo de evaluación. Como se puede observar en la figura I, el día 52, alcanzaron un pico máximo de aproximadamente 40\%. No obstante durante los últimos tres días de medición, sufrieron un descenso en su productividad, pasando del $40 \%$ al $30 \%$ de metano.

En caso del biodigestor 5 se observó una tendencia creciente durante todo el periodo de medición, llegando a alcanzar un porcentaje máximo de metano cercano al $50 \%$ en el día 55.

Los resultados obtenidos en la presente investigación con respecto a la producción de metano, reflejan que la combinación de desechos de origen humano y vegetal permitió obtener un mayor contenido de este gas (50\%), en comparación con lo que se produjo al utilizar solamente los desechos de origen humano (30\%). Estos resultados son comparables a los reportados por Rodríguez y colaboradores (1997), quienes obtuvieron una mayor productividad en los 


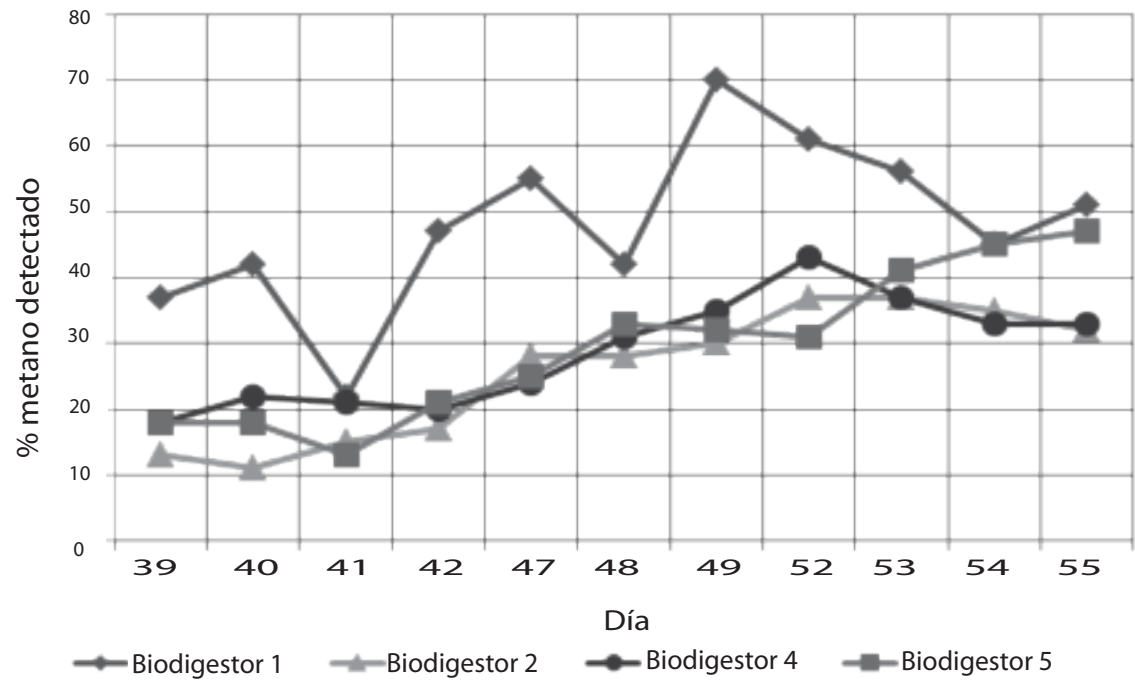

Figura I. Porcentaje de metano producido en los biodigestores a escala durante el periodo comprendido entre el día 39 y el día 55, después de haber iniciado la alimentación manual con desechos orgánicos.

biodigestores alimentados con una combinación de aguas servidas con estiércol de ganado y residuos de E. crassipes, en comparación con los biodigestores alimentados con una mezcla de aguas servidas y estiércol solamente.

Asimismo, otras investigaciones han demostrado que la codigestión de excretas animales con desechos de la agricultura o la agroindustria, da como resultado un fuerte incremento en la producción de biogás, ya que la combinación de ambos tipos de sustratos permite ajustar la proporción de carbono: nitrógeno a un radio de 30: I, que es lo ideal para promover el desarrollo de las comunidades metanogénicas (Rivas et al., 20 I0).

En conclusión, los desechos orgánicos de origen humano y vegetal que se encuentran en la planta de tratamiento del TEC, representan una fuente potencial para la obtención de energía renovable, la cual en un futuro, podría ser aprovechada a nivel institucional mediante el escalamiento del proceso de biodigestión que se llevó a cabo en esta investigación.

\section{Determinación de parámetros asociados a la degradación de materia orgánica}

En el cuadro 2 se presentan los resultados de la determinación de los parámetros asociados a la degradación de materia orgánica en los biodigestores a escala.
Con respecto a la temperatura, los efluentes de todos los biodigestores presentaron una temperatura menor a la de los respectivos influentes. El rango de temperatura de los efluentes osciló entre 19 y $19.8^{\circ} \mathrm{C}$, lo cual sugiere que la temperatura interna de los biodigestores fue baja, a pesar de que idealmente debería estar en el rango tolerado por los diferentes microorganismos $\left(20-55{ }^{\circ} \mathrm{C}\right)$. Las bacterias metanogénicas, específicamente, son más sensibles a los cambios de temperatura que los otros microorganismos del digestor, debido a que su velocidad de crecimiento es más lenta (Soria et al., 200I).

Un decrecimiento súbito en unos pocos grados podría retardar la producción de metano, sin afectar la actividad de las bacterias acidificantes, permitiendo una excesiva acumulación de ácidos (Osorio et al., 2007). Por lo tanto, se especula que el equilibrio bacteriano dentro de los biodigestores a escala pudo verse afectado por las condiciones ambientales.

Además de la temperatura, otro factor crítico para que la biodigestión se pueda dar de forma eficiente es el pH. Según Osorio y colaboradores (2007), lo ideal es que el $\mathrm{pH}$ oscile entre 6.5 y 8 . En los efluentes de los biodigestores 2 y 4 , el promedio del $\mathrm{pH}$ se mantuvo dentro de este rango (cuadro 2). Sin embargo, a la salida de los biodigestores I y 5 , el promedio del $\mathrm{pH}$ fue menor a 6.5, con valores de 6.28 y 6.25 respectivamente. Este resultado 
Cuadro 2. Parámetros físicos, biológicos y químicos asociados a la degradación de materia orgánica en los biodigestores a escala del TEC.

\begin{tabular}{|c|c|c|c|c|c|c|}
\hline \multirow{2}{*}{ Biodigestor } & \multirow{2}{*}{ Muestra } & \multicolumn{5}{|c|}{ Parámetro } \\
\hline & & T3 $\left( \pm 0,1^{\circ} \mathrm{C}\right)$ & $\mathrm{pH}( \pm 0,0 \mathrm{I})$ & DBO $(\mathrm{mg} / \mathrm{l})$ & DQO (mg/l) & ST $(\mathrm{mg} / \mathrm{l})$ \\
\hline \multirow[b]{3}{*}{ I } & Influente & 20,0 & 7,58 & $208 \pm 81$ & $480 \pm 67$ & $4647 \pm 14$ \\
\hline & Efluente & 19,5 & 6,28 & $447 \pm 16$ & $960 \pm 58$ & $|5| 5,0 \pm 8,4$ \\
\hline & $\begin{array}{l}\text { Cambio en el efluente } \\
\text { con respecto al } \\
\text { influente }\end{array}$ & -0.5 & -1.3 & $+115 \%$ & $+100 \%$ & $-67 \%$ \\
\hline \multirow[b]{3}{*}{2} & Influente & 23,5 & 7,04 & $166 \pm 2$ & $312 \pm 16$ & $583,0 \pm 7,1$ \\
\hline & Efluente & 19,5 & 7,07 & $28,0 \pm 1,1$ & $78,3 \pm 8,0$ & $325,0 \pm 7,0$ \\
\hline & $\begin{array}{l}\text { Cambio en el efluente } \\
\text { con respecto al } \\
\text { influente }\end{array}$ & -4 & +0.03 & $-83 \%$ & $-75 \%$ & $-44 \%$ \\
\hline \multirow[b]{3}{*}{4} & Influente & 23,2 & 7,30 & $176 \pm 16$ & $494 \pm 41$ & $1586,0 \pm 8,5$ \\
\hline & Efluente & 19,8 & 6,97 & $21,0 \pm 1,0$ & $59,0 \pm 7,1$ & $315,0 \pm 7,0$ \\
\hline & $\begin{array}{l}\text { Cambio en el efluente } \\
\text { con respecto al } \\
\text { influente }\end{array}$ & -3.4 & -0.33 & $-88 \%$ & $-88 \%$ & $-80 \%$ \\
\hline \multirow[b]{3}{*}{5} & Influente & 20,0 & 7,88 & $176 \pm 81$ & $576 \pm 67$ & $25|8,1 \pm 24|$, \\
\hline & Efluente & 19,0 & 6,25 & $641 \pm 163$ & $960 \pm 80$ & $\mid 191,0 \pm 9,0$ \\
\hline & $\begin{array}{l}\text { Cambio en el efluente } \\
\text { con respecto al } \\
\text { influente }\end{array}$ & -1 & -1.63 & $+264 \%$ & $+67 \%$ & $-53 \%$ \\
\hline
\end{tabular}

sugiere que en los biodigestores I y 5 hubo una digestión anaerobia ineficiente o incompleta, a pesar de que dichos biodigestores produjeron un mayor porcentaje de metano (figura I).

Por otro lado, en el agua, el grado de contaminación con materia orgánica se mide usualmente en valores de DBO y DQO (Osorio et al., 2007). En los efluentes de los biodigestores 2 y 4 hubo una disminución de ambos parámetros con respecto a los influentes. Sin embargo, en los efluentes de los biodigestores I y 5, sucedió lo contrario, es decir que los parámetros de salida fueron mayores. En el caso de la DBO se observó un aumento de $115 \%$ y $264 \%$ respectivamente. Para la DQO, el incremento fue de $100 \%$ y $67 \%$, respectivamente.

El parámetro ST, que se refiere a la cantidad de partículas suspendidas o disueltas en el agua (Sánchez, 1995), disminuyó a la salida de todos los biodigestores, lo cual se atribuye a la conversión de los sólidos orgánicos a materia gaseosa, ya que todos los biodigestores produjeron metano.

Analizando en conjunto los resultados obtenidos en los efluentes de los biodigestores I y 5 con respecto a los parámetros de temperatura, $\mathrm{pH}$ y demanda de oxígeno, se especula que, durante el periodo evaluado, los microorganismos metanogénicos estuvieron parcialmente inhibidos tanto por las bajas temperaturas internas (Soria et al., 200 I) como por la concentración de sólidos dentro de los biodigestores, ya que según Hilbert (1998), conforme aumenta la concentración de sólidos, disminuye la movilidad de las bacterias metanogénicas en el sustrato, lo cual reduce la eficiencia de la biodigestión. Por lo tanto, se cree que la producción de metano en los biodigestores I y 5 no fue óptima.

Sin embargo, considerando que estos presentaron una mayor producción de metano en comparación con los biodigestores 2 y 4 , se concluye que la combinación de desechos empleada en los biodigestores I y 5 presenta un alto potencial de generación de metano, aunque se deben optimizar las condiciones bajo las cuales se llevó a cabo el proceso de digestión anaerobia para aumentar aun más el porcentaje de metano que se podría llegar a obtener con dicha combinación de desechos.

Finalmente, al analizar todos los parámetros obtenidos en el caso de los biodigestores 2 y 4, y tomando en cuenta que estos produjeron un menor porcentaje de metano, se cree que dentro de ellos, se pudo dar un proceso de digestión anaerobia más eficiente en comparación con los biodigestores I 
y 5. Sin embargo, los residuos empleados para la alimentación de estos biodigestores, al ser ricos en nitrógeno, no presentaron una proporción carbono: nitrógeno óptima para promover una producción de metano mayor al $30 \%$.

\section{Conclusiones y recomendaciones}

Los resultados obtenidos en esta investigación demuestran que es posible obtener un porcentaje de metano relativamente alto a partir de una combinación de desechos de origen humano y vegetal obtenidos de la planta de tratamiento del TEC.

Para aumentar la eficiencia del proceso de digestión anaerobia, y por ende el porcentaje de metano obtenido a partir de estos desechos, se recomienda incrementar el tiempo de permanencia de los desechos orgánicos dentro de los biodigestores, es decir el tiempo de retención.

Además sería importante estudiar la productividad metanogénica de otras combinaciones de residuos que también se generan en la institución, como por ejemplo, los desechos de la soda comedor, con el fin de ampliar las posibilidades de generación energética limpia y renovable.

\section{Agradecimientos}

Algunos de los resultados presentados en este artículo forman parte del trabajo final de graduación desarrollado por la autora Rossy Guillén Watson como requisito parcial para obtener el grado académico de bachillerato universitario en Ingeniería en Biotecnología del TEC. Se agradece la ayuda técnica de María Alejandra Valerio García, Margie Faith Vargas, Carlos Solano Moya y Freddy Ángulo Ramírez.

\section{Bibliografía}

Antoni, D., Zverlov, V. \& Schwarz, W. (2007). Biofuels from microbes. Applied Microbiology and Biotechnology. 77, 2335.

Bidlingmaier, W. (2006). Fifth ORBIT Conference probes anaerobic digestion. BioCycle Journal of Composting and Organics Recicling. 47(9), 42-49.

Clesceri, L; Eaton, A; Greenberg,A \& Rice, E. (2005). Standard methods for the examination of water and wastewater. 2 Ist edition. Published jointly by the American Public Health Association, American Water Works Association and Water Environment Federation. USA. I368 pp.

Coto, J; Maldonado, J; Botero, R \& Murillo, J. (2005). Implementación de un sistema para generar electricidad a partir de biogás en la Earth. Tierra Tropical. 3(2), 129 138.

Deloya, A. (2009). Cumplimiento de la normativa en el sistema de tratamiento de aguas residuales del Instituto Tecnológico de Costa Rica. Tecnología en Marcha. 22( I), 50-56.

Hilbert, J. (1998). Manual para la producción de biogás. Instituto de Ingeniería Rural I.N.T.A. - Castelar. 57 pp.

Instituto Meteorológico Nacional. Costa Rica. (2008). Datos Climáticos. Consultado 22 dic, 2009. Obtenido desde: http://www.imn.ac.cr/IMN/MainAdmin.aspx?_EVENTT ARGET $=$ ClimaCiudad\&CIUDAD $=10$

Osorio, j; Ciro, H \& González, H. (2007). Evaluación de un Sistema de Biodigestión en Serie para Clima Frío. Revista Facultad Nacional de Agronomía, Medellín. 60(2), 4l 454162.

Rivas, O.; M. Faith \& Guillén R. (20 I0). Biodigestores: factores químicos, físicos y biológicos relacionados con su productividad. Tecnología en Marcha. 23(I), 39-46.

Rodríguez J.C., El Atrach, K., Rumbos, E. \& Delepiani, A.G. (1997). Resultados experimentales sobre la producción de biogás a través de la bora y el estiércol de ganado. Agronomía Tropical. 47(4), 44I-455.

Sánchez, L.E. (1995). Control de la contaminación de las aguas. Aspectos Geológicos de Protección Ambiental. Volumen I, Unesco. 17 pp.

Soria, M. J.; Ferrera-Cerrato, R.; Etchevers, J.; Alcántar, G.; Trinidad, J:; Borges, L. \& Pereyda, G. (200 I). Producción de Biofertilizantes Mediante Biodigestión de Excreta Líquida de Cerdo. Terra. 19(4), 354-36I.

Weiss, A; Jérôme, V.; Burghardt, D; Likke, L.; Peiffer, S.; Hoffstetter, E.; Gabler, R. \& Freitag, R. (2009). Investigation of Factors Influencing Biogas Production in A LargeScale Thermophilic Municipal Biogás Plant. Applied Microbiology and Biotechnology. 84(5), 987-I00 I. 
Tecnología en Marcha,

80 Vol. 25, N², Abril-Junio 2012 